\title{
Muscle function, physical function, and gait in older women with and without knee osteoarthritis
}

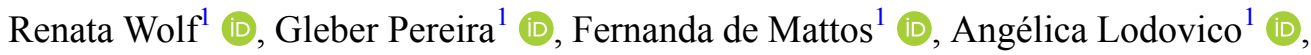 \\ Paulo Cesar Barauce Bento ${ }^{1}$ \\ ${ }^{I}$ Departmento de Educação Física, Universidade Federal do Paraná, Curitiba, PR, Brasil.
}

Associate Editor: Iane P. Novais, Universidade Estadual do Sudoeste da Bahia, Jequié, BA, Brasil.

\begin{abstract}
Aim: To compare muscle function of knee extensors, gait parameters, and physical function in older women with and without knee osteoarthritis (KOA) and to associate these parameters to the KOA incidence in this population. Methods: Sixteen older women with KOA $(66.9 \pm 5.5$ years; $74.9 \pm 10.0 \mathrm{~kg} ; 157.9 \pm 0.9 \mathrm{~cm} ; 30.2 \pm$ $5.0 \mathrm{~kg} / \mathrm{m}^{2}$ ) and fourteen healthy counterparts (control group: CG; $68.8 \pm 5.8$ years; $68.9 \pm 10.5 \mathrm{~kg} ; 158 \pm 0.06 \mathrm{~cm}$; $27.4 \pm 4.0 \mathrm{~kg} / \mathrm{m}^{2}$ ) participated in this study. Muscle function, physical function, and gait parameters were evaluated in both groups. The Western Ontario and McMaster Index (WOMAC) questionnaire was answered only by the KOA group. A correlation was performed to verify if KOA incidence was associated with muscle function, physical function, and gait parameters. Results: KOA group showed lower peak torque at $60 \% \mathrm{~s}(30 \% ; \mathrm{p}=0.003)$ and $180 \% \mathrm{~s}(37 \%$; $\mathrm{p}<0.001)$, greater acceleration time at $60 \% \mathrm{~s}(382 \% ; \mathrm{p}<0.001)$, lower cadence $(12.2 \% ; \mathrm{p}=0.002)$, slower gait speed $(19.5 \% ; \mathrm{p}<0.001)$ and greater stride time $(12.5 \% ; \mathrm{p}=0.001)$ than $\mathrm{CG}$ group. However, there was no difference between groups in physical function $(\mathrm{p}<0.0045)$. The KOA incidence presented a negative correlation with peak torque (rho $=-0.602 ; \mathrm{p}<0.001)$, cadence (rho $=-0.533 ; \mathrm{p}=0.002)$, gait speed (rho $=-0.633 ; \mathrm{p}<0.001$ ), stride length ( $r h o=-0.517 ; \mathrm{p}=0.003$ ) and a positive correlation with stride time ( $\mathrm{rho}=0.533 ; \mathrm{p}=0.002$ ) and acceleration time (rho $=0.655 ; \mathrm{p}<0.001)$. Conclusion: Our findings suggest that knee osteoarthritis may impair the function of the knee extensors muscles and gait parameters. An association between the ability to produce force rapidly and gait speed with the KOA incidence in older women was also observed.
\end{abstract}

Keywords knee joint, mobility, older adults.

\section{Introduction}

The prevalence of knee osteoarthritis (KOA) increases with age, and it is the most common joint disease that causes mobility limitations ${ }^{1}$. Older women are more likely to develop KOA than $m^{2}$, and decreased muscle quadriceps strength has been associated with increased pain, cartilage loss, and reduced physical function in this population compared to healthy age-matched controls ${ }^{3-5}$. Moreover, activation of the quadriceps muscles before the heel strike in walking may protect the musculoskeletal system and the knee joint ${ }^{6,7}$. Thus, quadriceps strength has been considered a primary risk factor for the progression of joint damage in persons with $\mathrm{KOA}^{8}$.

Activities of daily living, such as walking, climbing stairs, and rising from a chair demand muscle strength and the ability to develop force rapidly in a short period ${ }^{9,10}$. However, a muscle contractile velocity reduction is observed in older adults compared to younger individuals ${ }^{11-13}$. In addition, the decline in quadriceps muscle contractile velocity may occur before its strength reduction, deteriorating functional performance in the early stages of senescence ${ }^{14,15}$. Acceleration time, defined as "the time required to accelerate to a preset dynamometer speed," provides valuable information regarding muscular capacity to produce maximal muscle action quickly ${ }^{16}$. It may be associated with the decline in the ability to perform activities of daily living. However, the changes in acceleration time in older adults with KOA are unknown. Besides the relevance of quadriceps strength and contractile velocity, gait speed is considered an essential parameter for keeping independence through life ${ }^{17}$. Gait speed is associated with survival in older adults, with significant increments per $0.1 \mathrm{~m} / \mathrm{s}^{18}$. However, KOA incidence induces to nine times the high probability of having a faster decline in gait speed, approximately $2.5 \%$ per year ${ }^{19}$.

The older adults with KOA have shown a decrease in the knee extensors' peak torque and acceleration time, lower physical function, and worse gait parameters than healthy older adults. Moreover, previous studies have shown a relationship between knee extensors muscle function, gait parameters, and decreased physical function in healthy older adults ${ }^{3,10,20}$. For example, knee extensor weakness may, to some extent, account for the difficulty and increased time required to stand from a seated position 
in older adults with KOA and mobility limitations ${ }^{21,22}$. Hence, it is plausible to expect that older adults with KOA may present more significant impairment than healthy older adults, suggesting a negative impact on daily living activities $^{23}$. However, it is not clear in the literature if muscle function of knee extensors, physical function, and gait parameters are associated with the KOA occurrence in older adults ${ }^{8}$.

Therefore, this study aimed to compare knee extensor muscle function, gait parameters, and physical function in older women with and without KOA and associate them with the KOA incidence in this population. We hypothesized that (I) the older women with KOA would present worse muscle function of knee extensors, gait parameters, and physical function than older women with no KOA; and (II) all these variables would be associated with KOA incidence.

\section{Methods}

\section{Study population and design}

Sixteen older women with KOA and fourteen healthy age and gender-matched control participants were eligible for this study. Exclusion criteria were the presence of prosthesis in the lower limbs, historical fracture in the lower limbs, use of the assistive device during walking, osteoarthritis of hip or ankle. The KOA participants were recruited from a hospital of the university and the community. The inclusion crieteria were participants diagnosed with unilateral or bilateral knee osteoarthritis with radiological knee damage graded as I, II, and III according to the Kellgren-Lawrence scale ${ }^{24}$. Participants with bilateral KOA, the more symptomatic limb was tested (e.g., pain, joint stiffness, and crepitation) by self-report since the similarity in lower extremity mechanics between unilateral and bilateral KOA is sufficiently robust to consider both subsets as a single cohort ${ }^{25}$. Information on the pharmacological treatment of the participants with knee osteoarthritis was not obtained. Control participants were recruited only from the community, and the dominant limb was tested. The leg dominance was determined with the ball kick test, which consisted of asking the participants to kick a soccer ball with moderate intensity three times, and the leg used for most trials was considered as the dominant limb. The power of the study was calculated at post hoc considering: (i) one tail; (ii) normal parent distribution; (iii) 1.51 effect size $d$ from the difference between groups in the gait speed variable; (iv) maximum sampling error of 5\%; (v) sample size KOA group; (vi) sample size CG group. The power obtained was 0.98 . The Research Ethics Committee of the University approved the study (protocol number: 344.853). All participants signed an informed consent form to participate in the research and attended two days of testing, including the first-day physical char- acteristics assessment, 3D motion gait analysis, and the familiarization session of muscle function test. On the second day, participants performed muscle function and functional tests.

\section{Gait parameters analysis}

Kinematic data were conducted to determine the spatiotemporal gait parameters, such as cadence, velocity, stride length, and stride time. Gait assessment was performed on a level surface of $9 \mathrm{~m}$ longer in the laboratory's data collection area with a motion capturing system (Vicon ${ }^{\circledR}$, Oxford, UK), consisting of ten T10 infrared optoelectronic cameras sampling at $100 \mathrm{~Hz}$. The calibration was performed according to manufacturer recommendations and yielded a volume of $3 \mathrm{~m}$ long, $1.5 \mathrm{~m}$ wide, and $1.7 \mathrm{~m}$ in height. Data were collected using the Plug-in-gait sacrum model of lower limbs ${ }^{26}$. Participants were encouraged to walk barefoot at a self-selected pace and performed a brief warm-up to accommodate initial variations in gait speed and ensure that participants were walking at their comfortable speed. Participants performed ten walking trials each, and spatiotemporal gait variables were calculated through the average of three first valid trials. The time series were normalized to $100 \%$ of total stride time using a spline function (Matlab R2009a(C), USA), considering two successive foot strikes of the more symptomatic limb in the KOA group and two successive foot strikes of the dominant limb in the control group.

\section{Muscle function of the knee extensors evaluation}

Peak torque was measured in the knee extensors using an isokinetic dynamometer (Biodex System 3; Biodex Medical Systems). Participants were positioned against the backrest of the stationary seat with a hip angle of $85^{\circ}$, and stabilizing belts were placed across the participant's chest and waist. The input shaft of the dynamometer was aligned with the axis of rotation of the participant's knee. The dynamometer was set in concentric mode at angular velocities of $60^{\circ} / \mathrm{s}^{-1}$ and $180^{\circ} / \mathrm{s}^{-1}$.

The older women performed three submaximal practice efforts before maximal trials. All participants received the same instructions for the test: "to perform the movement as faster and stronger as they could". The test consisted of 3 repetitions at each angular velocity, with a rest period of $120 \mathrm{~s}$ between velocities ${ }^{27}$. The greatest peak torque $(\mathrm{N} . \mathrm{m} / \mathrm{kg})$ at $60 \% \mathrm{~s}$ and $180^{\circ} / \mathrm{s}$ was calculated using a customized routine (Matlab R2009a C, USA) and considered for data analysis. Acceleration time (ms) was determined as the lowest time to reach the peak torque among three trials through curves analyses by BIODEX software.

\section{Physical function}

All participants performed the short physical performance battery (SPPB), which consists of three tests: three 
standing-balance trials to evaluate the static balance (tandem, semi-tandem, and side-by-side standing), five times sit to stand test to measure the lower limb strength (FTSST), and a 4-m walk to assess gait speed (4MWT). A score of 0 is the lowest level of physical function and 12 is the highest level of physical function ${ }^{28-30}$. The six-min walking test (6MWT), which measures the distance a person can walk on a level surface for $6 \mathrm{~min}^{31}$, was performed to indirectly evaluate the aerobic capacity. Timed up and go test (TUG), which measures the time a participant takes to rise from a chair, walk $3 \mathrm{~m}$ away, turn around, return to the chair and sit down again ${ }^{32}$, was performed to assess the agility and dynamic balance of the participants. Whenever a participant was unable to complete a physical function test, she was excluded from the analysis of the respective test.

\section{Western Ontario and McMaster Index (WOMAC)}

The WOMAC osteoarthritis index is a valid and reliable tool for determining a disease-specific indicator of health status in KOA individuals ${ }^{34}$, which was translated and validated to Portuguese language ${ }^{35}$. It provides information on related symptoms in three domains in patients with $\mathrm{KOA}^{33}$, including a measure of pain (5 items), stiffness ( 2 items), and physical function (17 items), each item scored on a five-point Likert scale. Scores for each scale were calculated by summing the points of the individual items and higher scores represent worse health status.

\section{Statistical analysis}

Shapiro-Wilk test was applied and confirmed the data normality of anthropometric characteristics, peak torque, gait parameters, and physical function. Levene's test confirmed the homogeneity of the data. Anthropometric characteristics, peak torque, gait parameters, and physical function were compared between KOA and control groups applying the independent t-test. The Mann-Whitney U test was applied to compare acceleration time between groups. The effect size was determined based on Cohen's $d$ calculation for unpaired comparisons ${ }^{36}$. The effect size values of references were: $(>-0.20)$ trivial, $(>0.20)$ small, $(>0.50)$ moderate and $(>0.80)$ large effect. The WOMAC score was presented as mean and standard deviation only for the KOA group. The correlation between osteoarthritis and peak torque, acceleration time, gait parameters, and physical function was performed using Spearman's Rho test. The effect size values of references for the correlations were: negligible ( 0.00 to \pm $0.20)$; low $( \pm 0.21$ to \pm 0.40$)$, moderate $( \pm 0.41$ to \pm $0.70)$, high ( \pm 0.71 to \pm 0.90$)$, and very high $( \pm 0.91$ to 1.00). The level of significance of all tests after the Bonferroni correction was set at $\mathrm{p}<0.0045$. The software used for analysis was SPSS (version 20).

\section{Results}

Participant's characteristics and descriptive statistics are presented in Table 1. There was no difference in anthropometric characteristics between groups $(\mathrm{p}>0.0045)$.

There was a significant difference in peak torque at $60 \% \mathrm{~s}(\mathrm{t}=-3.290 ;=0.003)$ and at $180 \% \mathrm{~s}(\mathrm{t}=-3.713$; $\mathrm{p}=0.001)$, in which CG presented greater peak toque at both velocities compared to KOA $\left(60^{\circ} / \mathrm{s}: 30 \% ; d=-1.20\right.$; $\left.180^{\circ} / \mathrm{s}: 37 \% ; d=-1.30\right)$. In addition, there was difference in acceleration time at $60 \% \mathrm{~s}(\mathrm{U}=28.500 ; \mathrm{p}<0.001)$, in which KOA group presented greater acceleration time compared with CG (382\%). However, there was no difference in acceleration time at $180^{\circ} / \mathrm{s}(\mathrm{U}=84.500 ; \mathrm{p}=0.243)$ between groups. Results are shown on Figure 1.

All the participants were able to perform the physical function tests. There was no difference in the performance of SPBB $(\mathrm{t}=-2.171 ; \mathrm{p}=0.040)$, TUG $(\mathrm{t}=2.103$; $\mathrm{p}=0.046)$ and 6MWT $(\mathrm{t}=-2.998 ; \mathrm{p}=0.006)$ between groups. Physical function tests are presented in Figure 2.

There were differences between groups in cadence $(\mathrm{t}=-3.503 ; \mathrm{p}=0.002)$, gait speed $(\mathrm{t}=-4.104 ; \mathrm{p}<0.001)$ and stride time $(\mathrm{t}=3.573 ; \mathrm{p}=0.001)$, in which the KOA group presented lower cadence $(12.2 \% ; d=-1.28)$ and gait speed $(19.5 \% ; d=-1.51)$. In addition, KOA group showed a higher stride time $(12.5 \% ; d=1.32)$ compared to CG. There was no difference in stride length between

Table 1 - Anthropometric characteristics, grade and WOMAC score from knee osteoarthritis and its matched-control group.

\begin{tabular}{|c|c|c|c|}
\hline & $\begin{array}{c}\text { KOA } \\
N=16\end{array}$ & $\begin{array}{c}\text { CG } \\
\mathrm{N}=14\end{array}$ & $\mathbf{p}$ \\
\hline Age (years) & $66.90 \pm 5.50$ & $68.80 \pm 5.80$ & 0.36 \\
\hline Weight (kg) & $74.90 \pm 10.00$ & $68.90 \pm 10.50$ & 0.12 \\
\hline Height (m) & $1.57 \pm 0.09$ & $1.58 \pm 0.06$ & 0.79 \\
\hline BMI $\left(\mathrm{kg} / \mathrm{m}^{2}\right)$ & $30.20 \pm 5.00$ & $27.40 \pm 4.00$ & 0.09 \\
\hline \multicolumn{4}{|l|}{ Grade } \\
\hline Grade I (n(\%)) & $2(12.50 \%)$ & - & - \\
\hline Grade II (n(\%)) & $7(43.75 \%)$ & - & - \\
\hline Grade III (n(\%)) & $7(43.75 \%)$ & - & - \\
\hline Unilateral (n(\%)) & $9(56.75 \%)$ & - & - \\
\hline Bilateral $(\mathrm{n}(\%))$ & $7(43.75 \%)$ & - & - \\
\hline \multicolumn{4}{|l|}{ WOMAC } \\
\hline Pain (0-20 a.u.) & $8.40 \pm 4.90$ & - & - \\
\hline Joint stiffness (0-8 a.u.) & $3.80 \pm 1.80$ & - & - \\
\hline Physical function (0-68 a.u.) & $28.70 \pm 15.00$ & - & - \\
\hline Total score (0-92 a.u.) & $40.10 \pm 21.10$ & - & - \\
\hline
\end{tabular}

KOA: knee osteoarthritis group; CG: control group; WOMAC: Western Ontario and Mcmaster Universities Osteoarthritis Index; BMI: body mass index. 

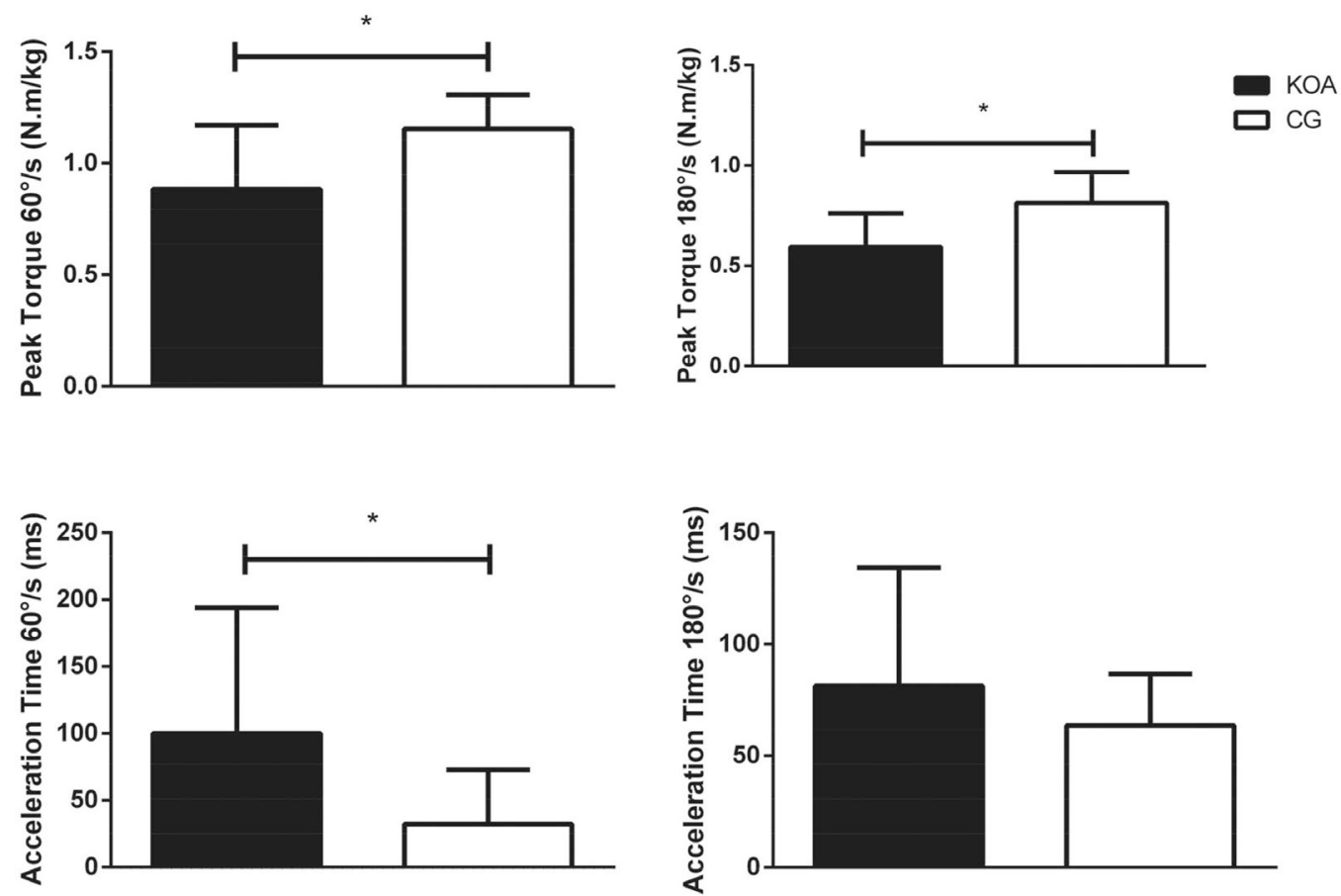

Figure 1 - Peak torque and acceleration time at $60 \%$ s and $180 \%$ s from knee osteoarthritis women $(\mathrm{n}=16)$ and its matched-control group $(\mathrm{n}=14)$. KOA: knee osteoarthritis group; CG: control group; *: level of significance $\mathrm{p}<0.05$
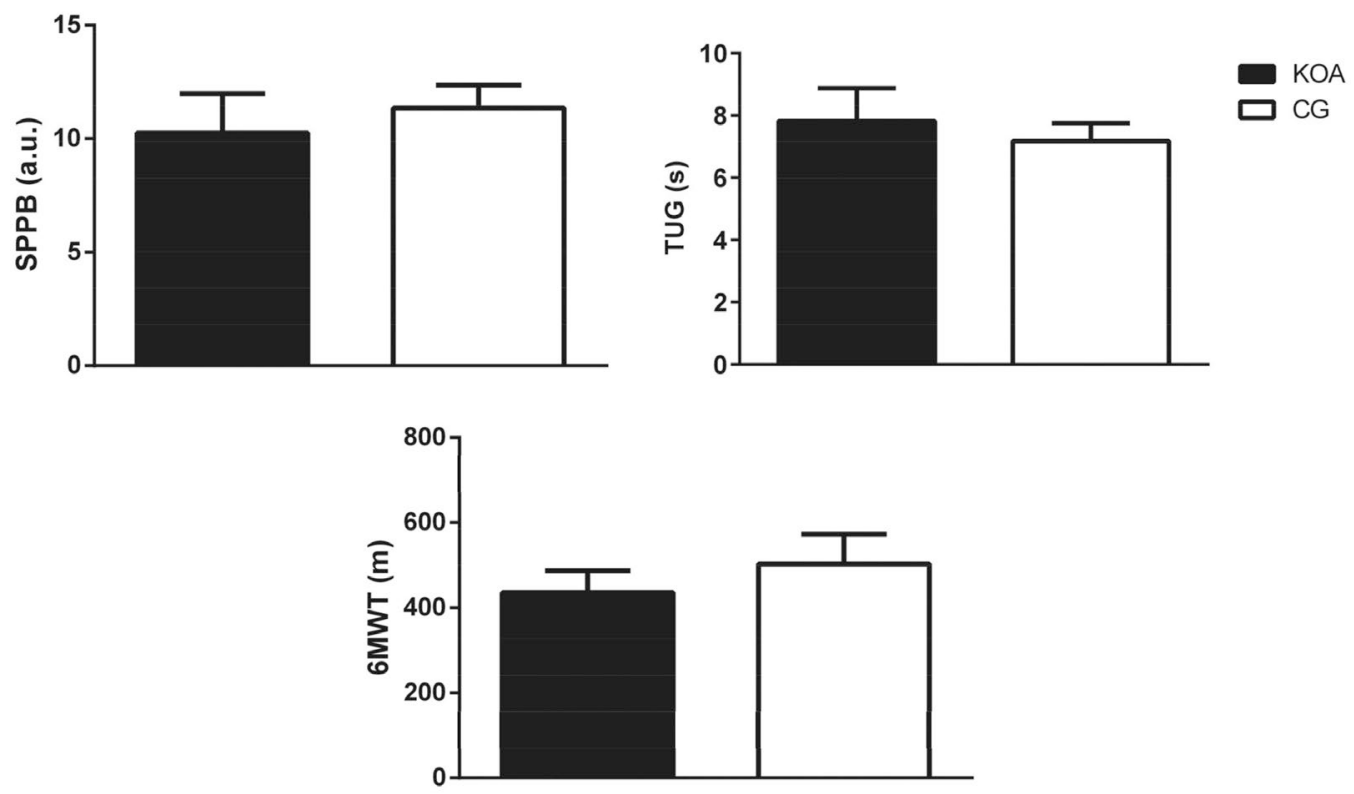

Figure 2 - Physical function from knee osteoarthritis women $(\mathrm{n}=16)$ and its matched-control group $(\mathrm{n}=14)$. SPPB: short physical performance battery; TUG: timed-up and go test; 6MWT: 6-minute walking test; KOA: knee osteoarthritis group; CG: control group.

groups $(\mathrm{t}=-3.062 ; \mathrm{p}=0.005)$. Results are presented in Table 2.

The correlation between the incidence of KOA, knee extensors muscle function, physical function, and gait parameters showed that lower cadence, gait speed, higher stride time, and higher acceleration time were significantly associated with KOA incidence. However, there were no correlations between the KOA incidence and peak torque at $60^{\circ} / \mathrm{s}$ and physical function. These results are presented in Table 3. 
Table 2 - Spatiotemporal gait parameters score from knee osteoarthritis and its matched-control group.

\begin{tabular}{lccc}
\hline & KOA & $\mathbf{C G}$ & \\
& $\mathbf{N}=\mathbf{1 6}$ & $\mathbf{N}=\mathbf{1 4}$ & $\mathbf{p}$ \\
\hline Cadence (steps/min) & $107.50 \pm 11.20$ & $122.50 \pm 12.20$ & $0.002^{*}$ \\
Gait speed (m/s) & $0.99 \pm 0.17$ & $1.23 \pm 0.14$ & $0.001^{*}$ \\
Stride time (s) & $1.12 \pm 0.11$ & $0.98 \pm 0.09$ & $0.001^{*}$ \\
Stride length (m) & $1.10 \pm 0.10$ & $1.21 \pm 0.08$ & 0.005 \\
\hline
\end{tabular}

KOA: knee osteroarthritis group; CG: control group.

Table 3 - Correlation between KOA occurrence and muscle function, physical function, and gait parameters.

\begin{tabular}{lc}
\hline & KOA \\
\hline Peak torque $60^{\circ} / \mathrm{s}$ & -0.471 \\
Peak torque $180^{\circ} / \mathrm{s}$ & $-0.602^{* *}$ \\
Acceleration time $60^{\circ} / \mathrm{s}$ & $0.655^{* *}$ \\
Acceleration time $180^{\circ} / \mathrm{s}$ & 0.217 \\
SPPB & -0.361 \\
TUG & -0.187 \\
6 MWT & -0.486 \\
Cadence & $-0.533^{*}$ \\
Gait speed & $-0.633^{*}$ \\
Stride time & $0.533^{*}$ \\
\hline
\end{tabular}

KOA: knee osteoarthritis; SPPB: short physical performance battery; TUG: timed-up and go test; 6MWT: 6-min walking test. ${ }^{*} \mathrm{P}<0.05$.

\section{Discussion}

The present study aimed to compare knee extensors muscle function, gait parameters, and physical function in older women with and without KOA, and the relationship of these parameters with the KOA incidence. The results showed that individuals with KOA presented lower peak torque, acceleration time, and a decline in gait parameters than their counterparts with no KOA. Moreover, only peak torque at $180 \%$, acceleration time at $60 \%$, and gait parameters were associated with KOA incidence.

Peak torque at both velocities differs between groups similar to previous studies ${ }^{3,5}$. In addition, the reduction of the number and size of muscle fiber, especially in fasttwitch muscle fibers, in older adults with KOA compared to healthy counterparts was documented previously ${ }^{37}$, which may explain the higher acceleration time observed for the KOA group compared to CG. Moreover, lower acceleration time is an essential factor in maintaining independence in activities of daily living ${ }^{9,10}$ and preventing falls, once the rapid force production is required to recover the balance after a trip or a $\operatorname{slip}^{38}$. The difference in acceleration time between groups disagrees with the previous study, in which the rate of torque development was similar between the two groups ${ }^{39}$. Although the rate of torque development and acceleration time provide information about fast muscle contraction capacity, the nature of the muscle action differs (dynamic vs. isometric), which may explain the discrepancy of the results. In addition, only women participated in the present study, and women are more prone to present a greater decline in muscle function than men ${ }^{40}$. Thus, older women with KOA show worse muscle function than healthy older women.

The physical function did not differ between the KOA group and CG, even though the scores of the KOA group of TUG and SPPB tests in the KOA group suggest poor balance and physical function. These results were not consistent with those observed in the acceleration time since the capacity to produce fast torque is strongly associated with functional performance ${ }^{9,10}$. On the other hand, the lack of physical function difference between the groups may be explained by the self-reported good physical function observed in the WOMAC questionnaire for the participants with KOA. The KOA group also reported low pain and low joint stiffness, which may contribute to good performance on the functional tests. Moreover, the KOA group presented knee osteoarthritis in mild and moderate degrees, which may not yet have influenced physical function. Therefore, pain and joint stiffness may have an essential role in the physical function, while the decline in peak torque and worse acceleration time were not sufficient to decrease the physical function in older women with KOA. Despite both groups did not present physical function impairment, a previous study comparing groups of different muscle torque production levels $\left(60^{\circ} / \mathrm{s}\right)$ identified knee extensor strength values associated with a high risk of developing severe mobility limitation. Older women who present less than $1.0 \mathrm{~N} . \mathrm{m} / \mathrm{kg}$ were considered at high risk of severe mobility limitation, even when they were initially well-functioning, while those with more than $1.34 \mathrm{Nm} . / \mathrm{kg}$ were classified at low risk. Results between these scores represent a moderate risk to develop severe mobility limitation ${ }^{41}$. Thus, the KOA and CG older women of the present study may be considered with a high and moderate risk of severe mobility limitation, respectively.

The performance in the gait parameters was worse in the KOA group than the CG. The lower cadence, gait speed, and the greater stride time in the KOA group may also be related to a more conservative walking pattern to decrease the knee joint load and probably by the fear of feeling pain during the activity ${ }^{42}$. In the current study, the gait speed of the KOA group indicates that such older women are in the threshold of independence in daily activities $(0.99 \mathrm{~m} / \mathrm{s})$ since older adults that walk at $1.0 \mathrm{~m} / \mathrm{s}$ are considered physically functional, and speeds from $1.20 \mathrm{~m} / \mathrm{s}$ show increased survival ${ }^{18,43}$. Previous studies found higher self-selected gait speeds to older adults with KOA (graded as I, II, and III) between 1.09 and $1.27 \mathrm{~m} / \mathrm{s}^{39,41}$. The difference in gait speed between studies may be due to men's participation in the previous studies, while in the present 
study, only women were evaluated. Thus, older women with KOA showed less gait ability than CG, which may lead to dependence in daily living activities.

Another important finding of the present study was the correlation of peak torque at $180^{\circ} \mathrm{s}$, acceleration time, and gait parameters with the KOA occurrence. The decline in the capacity to develop force rapidly has been associated with the worse performance in daily living activities $^{9,10}$. Our results showed that this decline is more pronounced in older women with KOA than in healthy older women. Gait parameters are also related to independence in daily activities. This finding is relevant because spatiotemporal gait parameters are relatively simple measures and may be used even in a clinical context. Therefore, peak torque, acceleration time, and gait parameters may be considered as possible predictors of KOA and may contribute to identifying older women at risk to develop KOA.

The participation of only older women in the present study limits the generalization of the results to other populations (e.g., older men). On the other hand, older women are more prone to develop KOA than $\mathrm{men}^{2}$. There was no control over the pharmacological treatment of participants with KOA. However, all participants were able to perform all tests, and, probably, the possible pharmacological treatment did not influence the results in the study. Additionality, the low number of participants made it impossible to carry out a logistic regression to verify whether peak torque, acceleration time, and gait parameters can be predictors of the KOA incidence.

\section{Conclusion}

Our findings suggest that KOA may impair the function of the extensors muscles and gait paraminus. Moreover, the association between the ability to produce force rapidly and gait speed with the KOA incidence in older women was observed. Experimental studies are required to confirm if the improvements in these parameters can predict, prevent or reduce KOA progression.

\section{References}

1. van Baar M E, Dekker J, Lemmens AM, Oostendorp RAB, Bijlsma JWJ. Pain and disability in patients with osteoarthritis of hip or knee: The relationship with articular, kinesiological, and psychological characteristics. J Rheumatol. 1998;25:125-33.

2. Blagojevic M, Jinks C, Jeffery A, Jordan KP. Risk factors for the onset of osteoarthritis of the knee in older adults: a systematic review and meta-analysis. Osteoarthritis Cartilage. 2010;18:24-33.

3. Amin S, Baker K, Niu J, Clancy M, Goggins J, Guermazi A, et al. Quadriceps strength and the risk of cartilage loss and symptom progression in knee osteoarthritis. Arthritis Rheum. 2009;60:189-98.
4. Gür H, Çakin N. Muscle Mass, Isokinetic Torque, and Functional Capacity in Women With Osteoarthritis of the Knee. Arch Phys Med Rehabil. 2003;84:1534-41.

5. Serrão PRMS, Gramani-Say K, Lessi GC, Mattiello SM. Knee extensor torque of men with early degrees of osteoarthritis is associated with pain, stiffness, and function. Rev Bras Fisioter. 2012;16:289-94.

6. Jefferson RJ, Collins JJ, Whittle MW, Radin EL, O'Connor $\mathrm{JJ}$. The role of the quadriceps in controlling impulsive forces around heel strike. Proc Inst Mech Eng. 1990;204:21-8.

7. Slemenda C. Brandt KD, Heilman DK, Mazzuca S, Braunstein EM, Katz BP, et al. Quadriceps weakness and osteoarthritis of the knee. Ann Intern Med. 1997;127:97-104.

8. Øiestad BE, Juhl CB, Eitzen I, Thorlund JB. Knee extensor muscle weakness is a risk factor for the development of knee osteoarthritis. A systematic review and meta-analysis. Osteoarthr Cartil. 2015;23:171-7.

9. Valtonen AM, Po T, Manninen M, Heinonen A, Sipila S. Knee Extensor and Flexor Muscle Power Explains Stair Ascension Time in Patients With Unilateral Late-Stage Knee Osteoarthritis :A Cross-Sectional Study. Am Congr Rehabil Med. 2015;96:253-9.

10. Suetta C, Aagaard P, Rosted A, Jakobsen AK, Duus B, Kjaer M, et al. Training-induced changes in muscle CSA, muscle strength, EMG, and rate of force development in elderly subjects after long-term unilateral disuse. J Appl Physiol. 2004;97:1954-61.

11. Kirkwood RN, Resende RA, Gomes HA, Mingoti SA, Sampaio RF. Aplicação da análise de componentes principais na cinemática da marcha de idosas com osteoartrite de joelho. Rev Bras Fisioter. 2011;15:52-8.

12. Clarkson PM, Kroll W, Melchionda AM. Age, Isometric Strength, Rate of Tension Development and Fiber Type Composition. J Gerontol. 1981;36:648-53.

13. Pojednic RM, Clark DJ, Patten C, Reid K, Phillips EM, Fielding RA. The specific contributions of force and velocity to muscle power in older adults. Exp Gerontol. 2012;47:608-13.

14. Jakobi JM, Rice CL. Voluntary muscle activation varies with age and muscle group. J Appl Physiol. 93:457-62.

15. Klass M, Baudry S, Duchateau J. Age-related decline in the rate of torque development is accompanied by lower maximal motor unit discharge frequency during fast contractions. J Appl Physiol. 2008;104:739-46.

16. Chen W, Su F, Chou Y. Significance of Acceleration Period in a Dynamic Strength Testing Study. J Orthop Sports Phys Ther. 1994;19:324-30.

17. Cesari M. Role of Gait Speed in the Assessment. JAMA 2011;305:93-4.

18. Studenski S, Perera S, Patel K. Gait Speed and Survival in Older Adults. JAMA 2011;305:50-.

19. White DK, Niu J, Zhang Y. Is symptomatic knee osteoarthritis a risk factor for a trajectory of fast decline in gait speed? Results from a longitudinal cohort study. Arthritis Care Res. (Hoboken). 2013;65:187-94.

20. Lowry KA, Vallejo AN, Studenski SA. Successful Aging as a Continuum of Functional Independence : Lessons from Physical Disability Models of Aging. Aging Dis. 2012;3:5-15.

21. Lord SR, Murray SM, Chapman K, Munro B, Tiedemann A, D'Souza G, et al. Sit-to-stand performance depends on sen- 
sation, speed, balance, and psychological status in addition to strength in older people. J Gerontol Med Sci. 2002;57:539-43.

22. Segal NA, Boyer ER., Wallace R, Torner JC, Yack HJ. Association between chair stand strategy and mobility limitations in older adults with symptomatic knee osteoarthritis. Arch Phys Med Rehabil. 2013;94:375-83.

23. Felson D, Lawrence R, Dieppe P, Hirsch R, Helmic C, Jordan J, et al. Osteoarthritis : New Insights. Part 1: The Disease and Its Risk Factors. Ann Intern Med. 2000;133:637-9.

24. Kellgren J, Lawrence J. Radiological assessment of osteoarthritis. Ann Rheum Dis. 1957;16:494-501.

25. Messier SP, Beavers DP, Herman C, Hunter DJ, Devita P. Are unilateral and bilateral knee osteoarthritis patients unique subsets of knee osteoarthritis ? A biomechanical perspective. Osteoarthr Cartil. 2016;24:807-13.

26. Kadaba MP, Ramakrishnan HK, Wootten ME. Measurement of Lower Extremity Kinematics During Level Walking. J Orthop Res. 1990;8:383-92.

27. Brown LE, Weir JP. ASEP procedures recommendation I: Accurate assessment of muscular strength and power. JEP online 2001;4:1-21.

28. Guralnik J, Simonsick EM, Ferrucci L, Glynn RJ, Berkman LF, Blazer DG, et al. A short physical performance battery assessing lower extremity function: association with selfreported disability and prediction of mortality and nursing home admission. J Gerontol Biol Sci. 1994;49:85-94.

29. Nakano MM. Versão brasileira da short physical performance battery-sppb: adaptação cultural e estudo da confiabilidade. Campinas. Dissertação [Mestrado em Educação] - Universidade Estadual de Campinas; 2007.

30. Freire AN, Guerra RO, Alvarado B, Guralnik JM, Zunzunegui MV. Validity and Reliability of the Short Physical Performance Battery in Two Diverse Older Adult Populations in Quebec and Brazil. J Aging Health. 2012;24:863-78.

31. Rikli R, Jones J. Development and validation of a functional fitness test for community-residing older adults. J Aging Phys Act. 1999;7:129-61.

32. Podsiadlo D, Richardson S. The timed "Up \&amp; Go": A test of basic functional mobility for frail elderly persons. J Am Geriatr Soc. 1991;39:142-8.

33. Connell SMC., Kolopack P, Davis AM. The Western Ontario and McMaster Universities Osteoarthritis Index (WOMAC): A Review of Its Utility and Measurement Properties. Arthritis Care Res. (Hoboken) 2001;45:453-61.

34. Jinks C, Jordan K, Croft P. Measuring the population impact of knee pain and disability with the Western Ontario and McMaster Universities Osteoarthritis Index (WOMAC). Pain. 2002;100:55-64.

35. Fernandes MI. Tradução e validação do questionário de qualidade de vida específico para osteoartrose womac (Wes- tern Ontario and McMaster Universities) para a língua portuguesa. São Paulo. Dissertação [Mestrado em Medicina]Universidade Federal de São Paulo; 2002.

36. Nakagawa S, Cuthill IC. Effect size, confidence interval, and statistical significance: a practical guide for biologists. Biol Rev. 82:591-605.

37. Aagaard P, Simonsen EB, Andersen JL, Magnusson P, Dyhre-Poulsen P. Increased rate of force development and neural drive of human skeletal muscle following resistance training. J Appl Physiol. 2002;93:1318-26.

38. Bento PCB, Pereira G, Ugrinowitsch C, Rodacki ALF. Peak torque and rate of torque development in elderly with and without fall history. Clin Biomech. 2010;25:450-4.

39. Winters JD, Rudolph KS. Quadriceps rate of force development affects gait and function in people with knee osteoarthritis. Eur J Appl Physiol. 2014;114:273-84.

40. Balogun S, Winzenberg T, Wills K, Scott D, Jones G, Aitken D, et al. Prospective associations of low muscle mass and function with 10-year falls risk, incident fracture and mortality in community-dwelling older adults. J Nutr Heal Aging. 2017;21:843-8.

41. Manini TM, Visser M, Won-Park S, Patel KV, Strotmeyer ES, Chen $\mathrm{H}$, et al. Knee extension strength cutpoints for maintaining mobility. J Am Geriatr Soc. 2007;55:451-7.

42. Sowers M, Jannausch ML, Gross M, Karvonen-Gutierrez CA, Palmieri RM, Crutchfield M, et al. Performance-based physical functioning in African-American and Caucasian women at midlife: considering body composition, quadriceps strength, and knee osteoarthritis. Am J Epidemiol. 2006;163:950-8.

43. Abellan Van Kan G, Rolland Y, Andrieu S, Bauer J, Beauchet $\mathrm{O}$, Bonnefoy $\mathrm{M}$, et al. Gait speed at usual pace as a predictor of adverse outcomes in community-dwelling older people an International Academy on Nutrition and Aging (IANA) Task Force. J Nutr Health Aging. 2010;13:881-9.

Corresponding Author Renata Wolf, Universidade Federal do Parana, Departamento de Educação Física, Av. Cel. Francisco H. dos Santos 100, Jardim das Américas, Curitiba, PR, Brasil.

E-mail: renata.wolf@gmail.com.

Manuscript received on May 30, 2020

Manuscript accepted on March 1, 2021

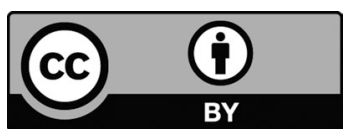

Motriz. The Journal of Physical Education. UNESP. Rio Claro, SP, Brazil - eISSN: 1980-6574 - under a license Creative Commons - Version 4.0 